\title{
Modelling and Correction of Influences on Surface Temperature Measurements using infrared thermography for animal health and welfare assessments
}

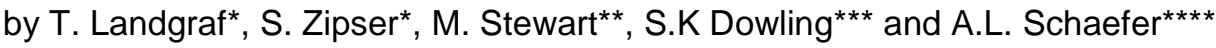 \\ *Fraunhofer IVI, Zeunerstr. 38, 01069 Dresden, Germany, tom.landgraf@ivi.fraunhofer.de \\ **InterAg, P.O. Box 9466, Hamilton 3240, New Zealand, mairi.stewart@interag.co.nz \\ *** AgResearch Ltd, 10 Bisley Road, Private Bag 3123, Hamilton 3214, New Zealand, \\ suzanne.dowling@agresearch.co.nz \\ **** University of Alberta, Edmonton, AB T6G 2R3, Canada, alschaef@telus.net
}

\begin{abstract}
For specific applications of infrared thermography (IRT) in the field of human medicine diagnosis, well defined standard operating procedures are used (e.g. controlled ambient conditions). In contrast, when IRT is used in the veterinary and animal science field, examinations are not always performed under controlled ambient conditions. This leads to unavoidable influences to the surface temperatures measured with IRT. This paper quantifies this effect and proposes a novel modelling and correction approach. This approach results in a significant increase in the quality of the data and provides a more accurate measurement of IRT for assessing animal health and welfare.
\end{abstract}

\section{Introduction}

Infrared thermography (IRT) is a useful non-invasive tool for diagnostic as well as health and welfare monitoring of animals [1]. Since the beginnings in 1956, new technical developments have led to increased image quality and a decline in the cost for IRT camera systems, making it more affordable for use in animal health and welfare applications. IRT has been used for many medical and veterinary applications (See [2] for recent examples).

Specifically the claw and udder temperature of dairy cows as well as the eye temperature were exemplary discussed here. The udder surface temperature is promising for the automatic detection of mastitis [3, 4]. The early detection of lameness and claw diseases based on the claw temperature seams possible as well [5]. The eye temperature of cattle has been shown to be a useful anatomical area to examine temperature changes in response to pain [6], stress [7] and the onset of disease [2,8]. This is mainly due to the rich capillary beds around the eye and the advantage of having no interference of fur, dust and dirt found on other areas of the body. In brief, Stewart et al. 2008 found that a drop in eye temperature in response to acute pain was caused by redirection of blood from the capillary beds via sympathetically-mediated vasoconstriction. In contrast, the eye temperature increases in response to metabolic changes during the onset of disease in calves [8].

These exemplary measurements of claw, udder and eye temperature changes require recording of individual animals over time, like many measurements for other species or diagnostic concerns as well. The varying ambient conditions are a disturbing influence to the time series analyses. This is obvious for hard environmental conditions (figure 1) but as shown later it is also relevant for normal ambient condition changes due to weather and seasons. The larger the ambient condition changes (the longer the time series) the larger the effect on the measurements

Veterinary applications comprising the analysis of time series in general require precise and absolute temperature measurements ${ }^{1}$, similar to conventional body temperature measurements with a thermometer. This absolute temperature measurement gives the reproducibility and the comparability in principle [9]. According to the IRT state of the art, an absolute radiometric temperature measurement requires beside others a calibrated camera. In addition the

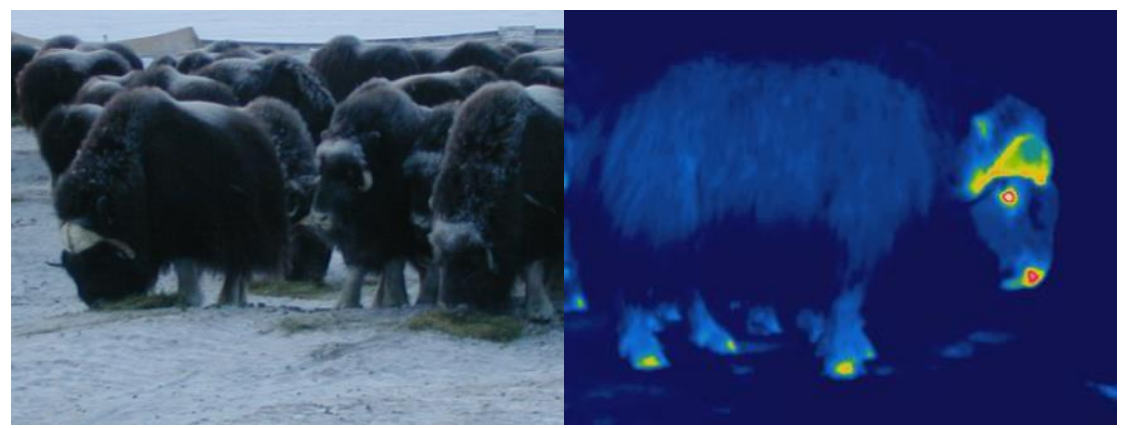

Fig. 1. Canadian Muskox at extreme ambient temperature of $-43^{\circ} \mathrm{C}$ (left: photo, right: IR-image)

\footnotetext{
${ }^{1}$ Other IRT applications do not require absolute measurements e.g. symmetry analysis of temperature patterns.
} 
compensation of background radiation is common. It calculates the real surface temperature of the object $T_{\text {obj,s }}$ based on the temperature measured by the camera $T_{\text {obj, }}$, the emissivity factor $\varepsilon$, the atmospheric transmission $\tau$ and the ambient temperature $T_{a m b}$ (see figure 2). Common IRT camera software is designed to calculate this correction ${ }^{2}$. But as many investigations show, the absolute surface temperatures still correlates with the ambient conditions. Hence for human medicine, constant ambient conditions are obligatory. For animal health and welfare assessments (e.g. mastitis, lameness, disease diagnosis), changing environmental conditions are normal and often involve bringing animals in from outdoors, in which case solar loading becomes a factor, or collecting images in semi-outdoor areas. For example, animals are brought into a milking shed, yard or restraining chute that may not be completely protected from rain or wind, and other factors such as the use of hoses for cleaning purposes creates varying levels of temperature and relative humidity. This restricts the analysis of long-term examinations, due to an increased span of ambient conditions.

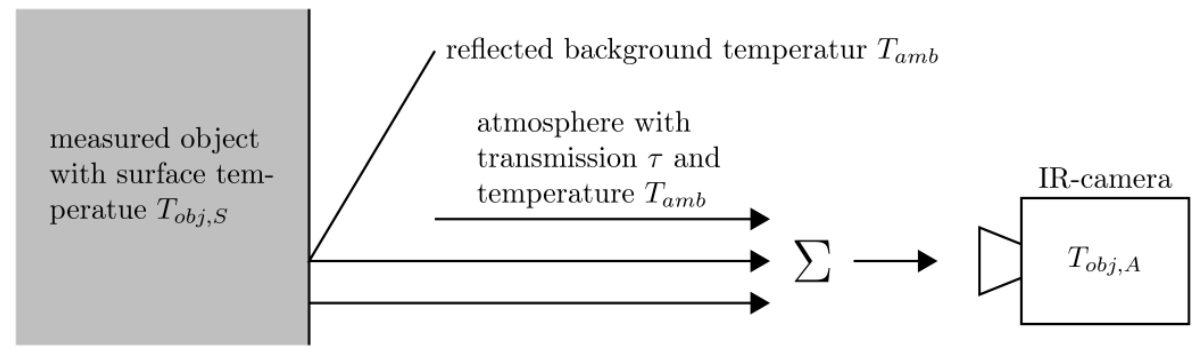

Fig. 2. Correction of background radiation in IRT

The state of the art names the ambient temperature, air humidity and air movement as relevant influences. But a quantification of these influences or a correction model is not yet known. This paper provides a quantification of the ambient influences based on long-term measurements and suggests a novel correction model.

\section{Quantification of the Ambient Condition Influences}

To model the influence of ambient conditions an anatomically motivated model is proposed [10]. Therefore a physical layer model is defined (figure 3). The basic layer is of the diagnostic relevant temperature $\mathrm{T}_{\text {diag }}$ and represents the anatomic structure of interest (e.g. the mammary gland or eye). It is assumed the diagnostic relevant temperature is constant, due to regulatory mechanisms. The basic layer is followed by layers representing the different tissue layers.
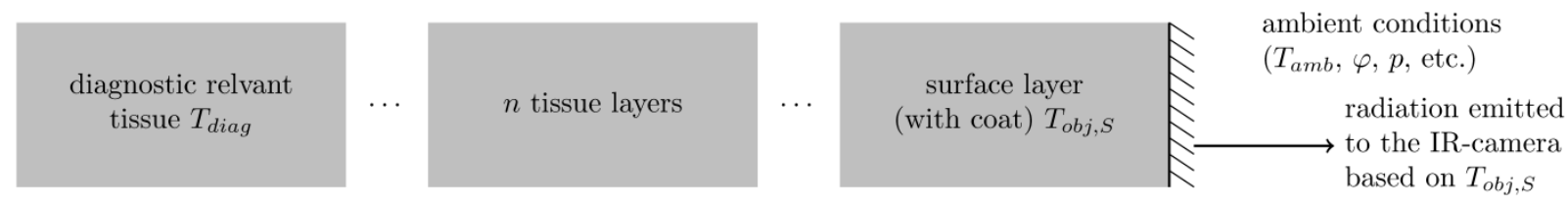

Fig. 3. Layer Model of the Surface Temperature Influences

Finally the surface layer of the temperature $T_{\text {obj,S }}$ emits radiation registered by the IR-camera as shown in figure 2 . This layer model could be transferred in a thermo electric circuit (figure 4). Assuming the acclimatised state (steady state condition, no temperature change but heat flow) this leads to a linear relation between $T_{\text {diag, }}, T_{\text {obj,s }}$ and $T_{\text {amb }}$. The model illustrates first that a changed ambient temperature $T_{\text {amb }}$ tunes the thermal equilibrium and results in a different surface

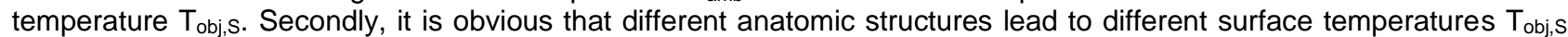
as well. This means the models are specific for anatomic regions.

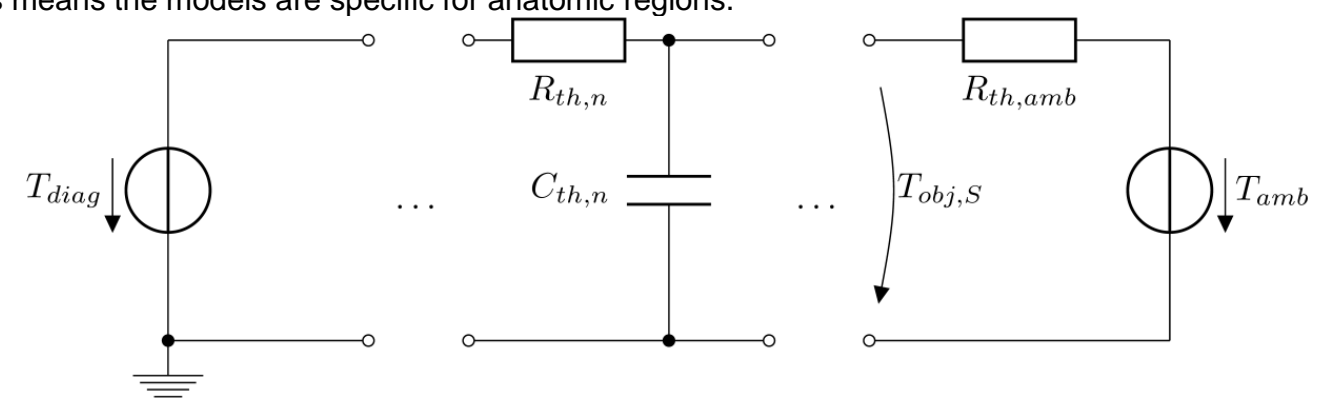

Fig. 4. Layer Model represented as a Thermo Electric Circuit

\footnotetext{
${ }^{2}$ Higher precision can be obtained using an additional reference body.
} 
The coefficients of the linear model comprise the thermal resistances of the different layers $R_{\text {th, } n}$ and of the transition from surface to air $\mathrm{R}_{\mathrm{th}, \mathrm{amb}}$. A quantification of the coefficients requires the thermal parameters of the model as well as knowledge about the particular anatomic structure of the animal. Neither of the thermal parameters are known from the state of the art nor could the individual animal structures be evaluated with justifiable effort. Therefore, this model is hardly applicable and a phenomenological approach is proposed [10]. The basic idea of the data driven approach is to calculate the relationship between the IR-temperature features and the ambient conditions using a regression model. With the help of the regression model, the data could be normalized to reference conditions.

The first step was to provide a valid database to quantify the ambient influence. Besides the IR-images, the varying ambient conditions were monitored alongside several long term IR temperature recordings during different animal health and welfare assessments. Ambient temperature $T_{a m b}$, humidity $\varphi$ and air pressure $p$ were recorded using a state of the art climate logger. Air speed was recorded using an ultrasonic anemometer placed beside the area spotted by the IR camera. In addition, the temperature humidity index (THI), popular in the classification of heat stress [11], was calculated:

$$
T H I=0.8 \frac{T_{a m b}}{{ }^{o} \mathrm{C}} \varphi\left(\frac{T_{a m b}}{{ }^{\circ} \mathrm{C}}-14.4\right)+46.6
$$

The analyses were performed on a dataset from different studies. In the first test series, udder and claw regions of 485 dairy cows were monitored over 100 days. The segmentation and calculation of IR temperature features was performed using automatic image processing $[12,13]$. The dataset consists of about 49,000 sequences with approx. 2 million IR images. The second series of eye temperatures comprise data from 18 sheep, which were monitored to examine a simulated stress response.

As a first step, a analyses using Pearson's correlation (Table 1) provides an indication of which ambient influences have a significant effect on the IR features. The mean surface temperature of the dairy cow claws shows the highest correlation coefficient of about 0.83 . The correlations show remarkable differences between the different IRfeatures and regions. It is noticeable that the temperature deviation is more robust against ambient influences. Where ambient temperature and THI show high correlations as expected, air pressure and speed show low values. We expected that air speed would have more of an influence on IR temperatures. Indeed [14] reported a decrease in eye temperature in response to increasing wind speed. The effects of wind speed on IR temperatures warrant further investigation.

Table 1. Correlation of selected IR temperature features and ambient conditions

\begin{tabular}{|c|c|c|c|c|c|c|c|}
\hline $\begin{array}{c}\text { anatomic } \\
\text { region }\end{array}$ & IR temperature feature & $\begin{array}{c}\text { ambient } \\
\text { temperature }\end{array}$ & $\begin{array}{c}\text { relative } \\
\text { humidity }\end{array}$ & $\begin{array}{c}\text { air } \\
\text { pressure }\end{array}$ & $\begin{array}{c}\text { air } \\
\text { speed }\end{array}$ & THI & $\begin{array}{c}\text { number } \\
\text { of } \\
\text { datasets }\end{array}$ \\
\hline \multirow{3}{*}{$\begin{array}{l}\text { dairy cow } \\
\text { claw }\end{array}$} & mean temperature & 0.83 & -0.16 & $-0,13$ & $-0,03$ & 0,64 & 48993 \\
\hline & max. temperature & 0.52 & -0.10 & -0.01 & -0.07 & 0.41 & 48993 \\
\hline & deviation & -0.09 & -0.11 & 0.15 & -0.16 & -0.01 & 48993 \\
\hline \multirow{3}{*}{$\begin{array}{l}\text { dairy cow } \\
\text { udder }\end{array}$} & mean temperature & 0.65 & -0.23 & 0,06 & $-0,07$ & 0,52 & 49886 \\
\hline & max. temperature & 0.61 & -0.23 & 0.05 & -0.07 & 0.49 & 48993 \\
\hline & deviation & -0.32 & 0.08 & -0.06 & 0.03 & -0.24 & 48993 \\
\hline \multirow{2}{*}{$\begin{array}{l}\text { sheep } \\
\text { eyes }\end{array}$} & mean temperature & 0.54 & -0.47 & - & - & 0.52 & 18 \\
\hline & max. temperature & 0.50 & -0.32 & - & - & 0.51 & 18 \\
\hline
\end{tabular}

\section{Correction Model}

Based on a physical modeling and statistical analysis above the linear model regression:

$$
\mathrm{T}=C_{0}+\sum_{(x)} C_{x} \cdot x
$$

is proposed. Thereby $\mathrm{T}$ stands for the examined temperature feature (e.g. mean temperature), $\mathrm{x}$ represents the ambient influences (e.g. ambient temperature and THI) and $\mathrm{C}_{\mathrm{x}}$ stands for the regression coefficient. figure 5 shows the data distribution and resulting regression of the mean claw temperature against the ambient temperature. With a slope of $0.86 \mathrm{~K}$ per Kelvin ambient temperature change the effect is clear.

This regression could be used to correct the temperature features corresponding to reference conditions (here the mean ambient temperature marked by the dashed line in figure 5$)$. This leads to the proposed regression model $M(x)$ :

$$
\mathrm{T}_{\text {corr }}=T-\sum_{(x)} C_{x}\left(x-x_{r e f}\right)
$$


where $T_{\text {corr }}$ is the corrected temperature feature and $x_{\text {ref }}$ stands for the reference condition. The impact of this correction is shown in figure 6. Higher order models, e.g. $\mathrm{M}^{2}$ comprising the $\mathrm{x}^{2}$ terms, were tested as well (see [4] for details). A comparison of different models is given in table 2. As seen in figure 6 the standard deviation of the dataset is significantly reduced for the mean temperatures. The effect is lower for the maximum temperature but still remarkable. As expected from the correlation in table 1, the impact for the deviation is low. Comparing the different correction models, the use of $\mathrm{T}_{\mathrm{amb}}$ and $\mathrm{TH}$ have the largest impact. The additional benefit of using all ambient conditions and higher order models is negligible.

Table 2. Overall IR-feature deviation of the original data and different correction Models

\begin{tabular}{|l|l|r|r|r|r|r|}
\hline $\begin{array}{l}\text { anatomic } \\
\text { region }\end{array}$ & $\begin{array}{l}\text { IR temperature } \\
\text { feature }\end{array}$ & $\begin{array}{l}\text { deviation } \\
\text { raw data }\end{array}$ & $\begin{array}{l}\text { deviation } \\
\mathbf{M}\left(\mathbf{T}_{\text {amb }}\right.\end{array}$ & $\begin{array}{l}\text { deviation } \\
\mathbf{M}\left(\mathbf{T}_{\text {amb, }} \text { THI) }\right.\end{array}$ & $\begin{array}{l}\text { deviation } \\
\mathbf{M}(\text { all) }\end{array}$ & $\begin{array}{l}\text { deviation } \\
\mathbf{M}^{2} \text { (all) }\end{array}$ \\
\hline \multirow{2}{*}{$\begin{array}{l}\text { dairy cow } \\
\text { claw }\end{array}$} & mean temperature & $2.89 \mathrm{~K}$ & $1.60 \mathrm{~K}$ & $1.55 \mathrm{~K}$ & $1.55 \mathrm{~K}$ & $1.54 \mathrm{~K}$ \\
\cline { 2 - 7 } & max. temperature & $2.90 \mathrm{~K}$ & $2.48 \mathrm{~K}$ & $2.43 \mathrm{~K}$ & $2.42 \mathrm{~K}$ & $2.41 \mathrm{~K}$ \\
\cline { 2 - 7 } & deviation & $0.97 \mathrm{~K}$ & $0.96 \mathrm{~K}$ & $0.96 \mathrm{~K}$ & $0.93 \mathrm{~K}$ & $0.93 \mathrm{~K}$ \\
\hline \multirow{2}{*}{$\begin{array}{l}\text { dairy cow } \\
\text { udder }\end{array}$} & mean temperature & $2.40 \mathrm{~K}$ & $1.86 \mathrm{~K}$ & $1.84 \mathrm{~K}$ & $1.77 \mathrm{~K}$ & $1.76 \mathrm{~K}$ \\
\cline { 2 - 7 } & max. temperature & $1.92 \mathrm{~K}$ & $1.55 \mathrm{~K}$ & $1.54 \mathrm{~K}$ & $1.50 \mathrm{~K}$ & $1.49 \mathrm{~K}$ \\
\cline { 2 - 7 } & deviation & $0.74 \mathrm{~K}$ & $0.70 \mathrm{~K}$ & $0.70 \mathrm{~K}$ & $0.70 \mathrm{~K}$ & $0.70 \mathrm{~K}$ \\
\hline
\end{tabular}

The investigations show that the impact on the deviations is exceptional low where most temperature features show an impact comparable to the mean or maximum temperature. The use of a linear correction model comprising $\mathrm{T}_{\mathrm{amb}}$ and $\mathrm{THI}$ appears to be best choice.

Figure 7 shows the time series of the claw temperature of dairy cow at morning milking. Without the correction the increasing claw temperature due to the ambient condition change could be misinterpreted during the diagnostic process. The trend of the increasing ambient temperature is removed where single correctives reach absolute values of up to $6 \mathrm{~K}$.

\section{Summary and Outlook}

These findings provide, for the first time, quantification of ambient influences in practical animal health and welfare applications. The effect, especially for the common IR temperature features mean temperature and maximum temperature, was very strong even for moderate climate changes. The proposed correction model significantly reduces the deviation due to varying ambient conditions. This means a correction of these influences could gain a significant improvement to the downstream diagnostic process when assessing animal health and welfare.

The proposed linear model comprises the ambient temperature and THI covers more than $95 \%$ of the deviation due to varying ambient conditions. It has a simple, interpretable and physical plausible structure, and could be integrated in automated IRT measuring systems, as shown in [6]. The main drawbacks are that the coefficients were estimated data driven and were specific for the region, the IR feature and the location ${ }^{3}$. Before the correction could be applied, the varying ambient conditions need to be measured to calculate the coefficients. This could be resolved in further studies by proposing a self-learning model or a model extension that allows the estimation of more general parameters. These investigations are on-going. In conclusion, this novel correction approach improves data quality and enables more accurate measures of IR temperatures for use in animal health and welfare assessments.

\section{Acknowledgement}

Parts of these investigations were accomplished within the scope of the interdisciplinary VIONA project (www.viona-system.net) financed by the German Federal Ministry of Education and Research (BMBF, ID 03WKP04B). The authors are grateful to the industry partners: DIAS Infrared $\mathrm{GmbH}$, Ralle Landmaschinen $\mathrm{GmbH}$, and $\mathrm{Yoo} \mathrm{GmbH}$ as well as the hosting farm Methauer Agro AG and Großdrebnitzer Agrar GmbH.

\footnotetext{
${ }^{3}$ The investigations show an influence of the thermal conditions of the measurement locations, which leads to bran specific parameter sets.
} 


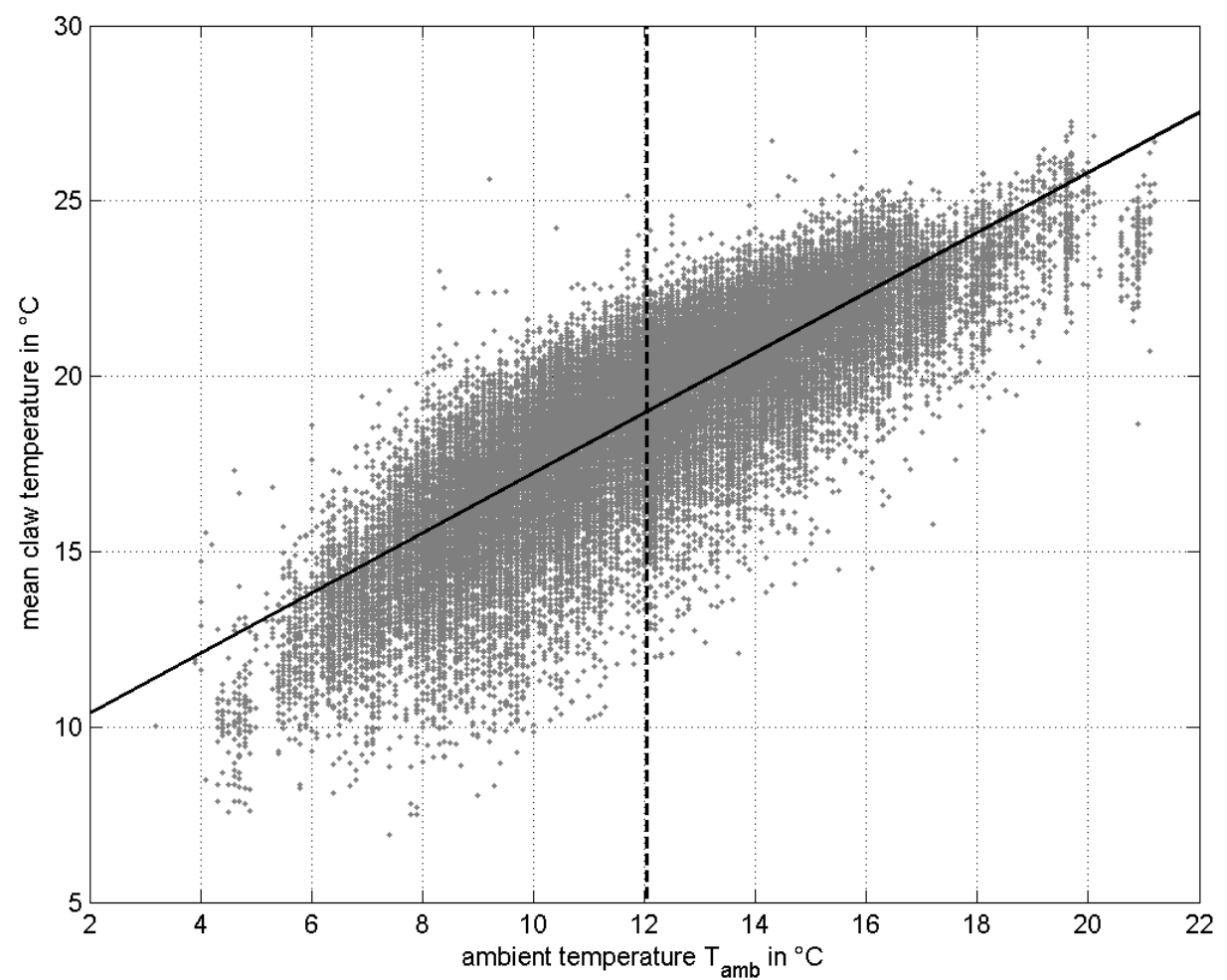

Fig. 5. ambient temperature influence to the mean claw temperature with the corresponiding regression (black line) and the reference ambient temperature (dashed lined)

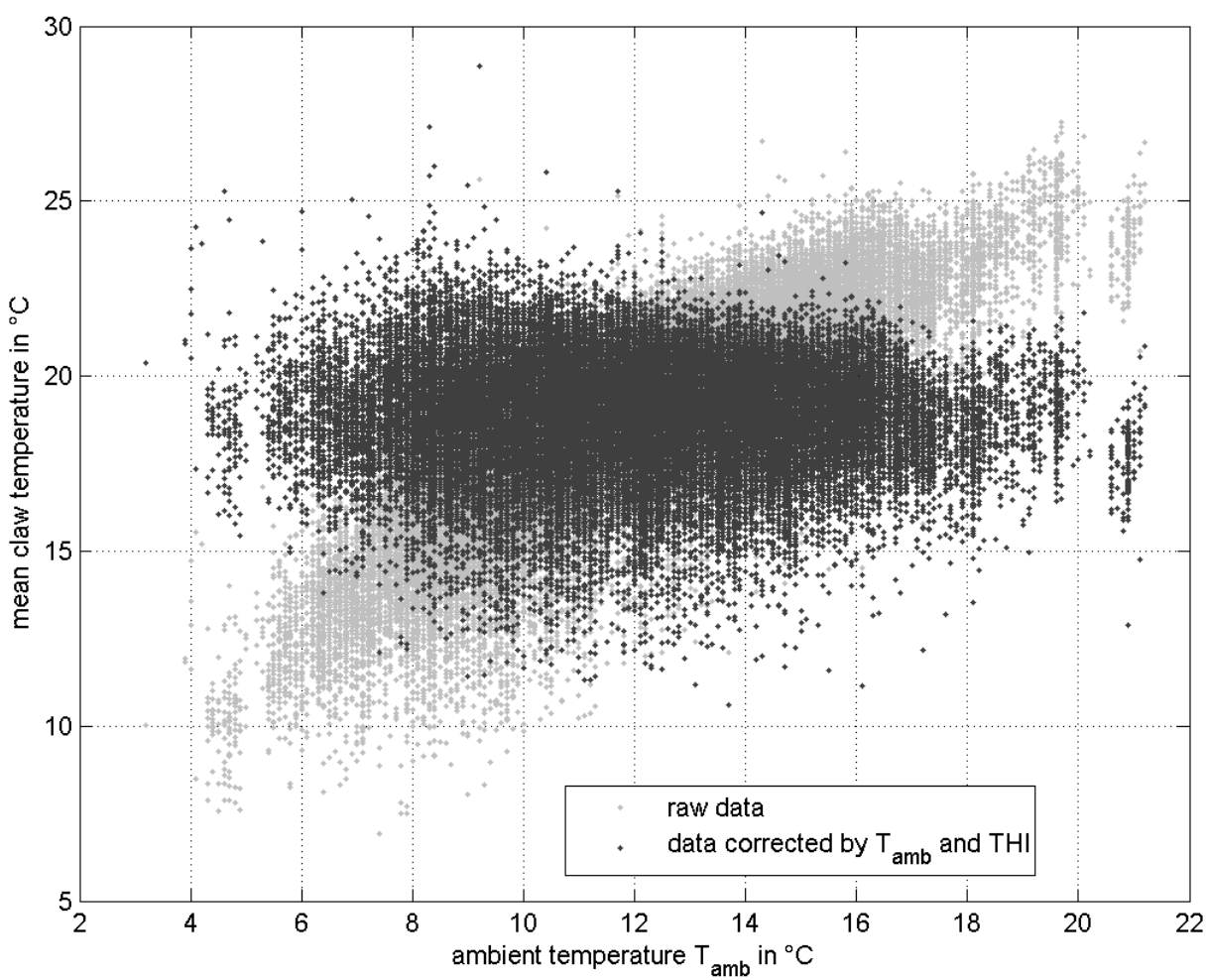

Fig. 6. mean claw temperature distribution corrected to the influence of Tamb and THI 


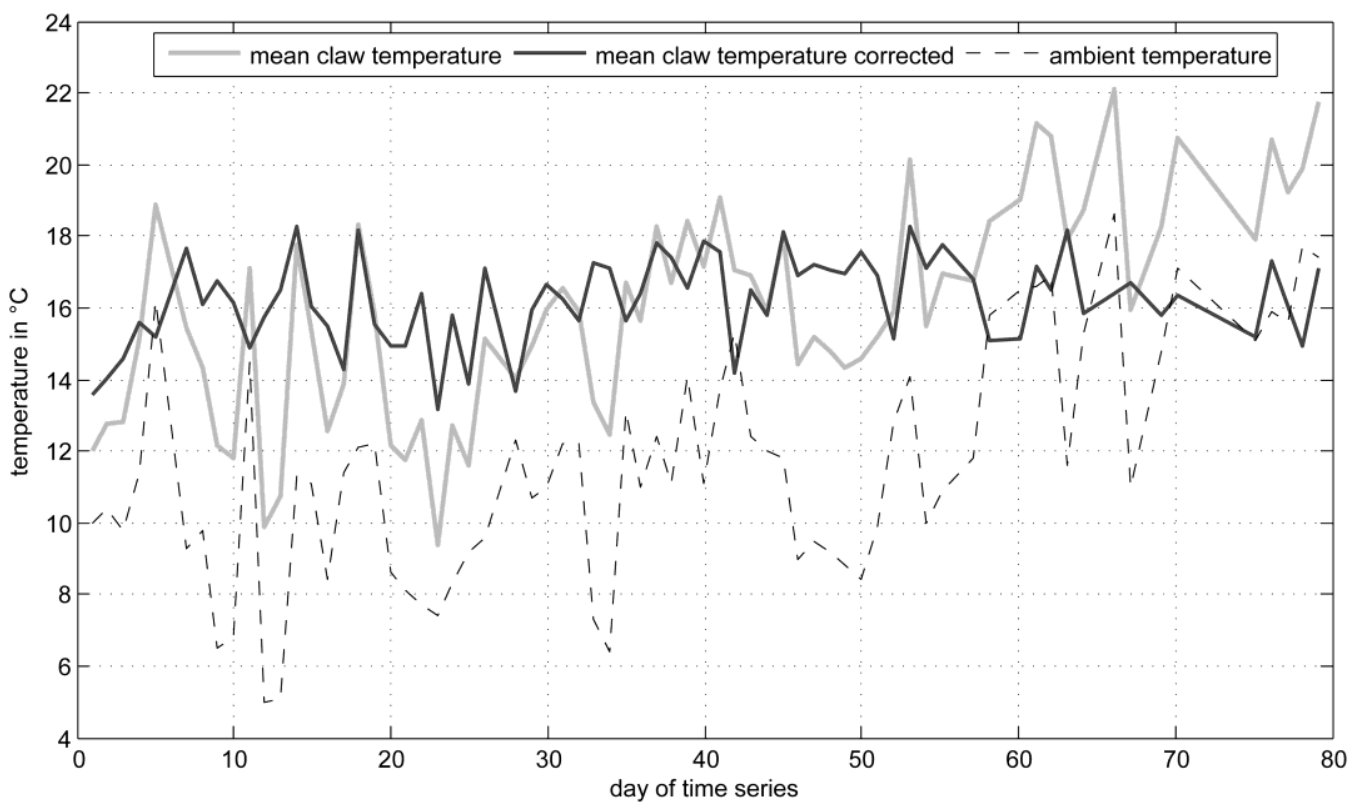

Fig. 7. time series of the mean claw temperature of one cow

\section{REFERENCES}

[1] Stewart, M., Webster, J.R., Schaefer, A.L., Cook, N.J., Scott, S.L.: Infrared thermography as a non-invasive tool to study animal welfare. Animal Welfare 14, 319-325; 2005

[2] Thermography. 2013. Current status and advances in livestock animals and veterinary medicine. Edited by F. Luzi, M. Mitchell, L.N. Costa and V. Redaelli. Brescia Foundation. Italy. ISBN 978-88-97562-06-1

[3] Metzner, Moritz ; Sauter-Louis, Carola ; Seemueller, Andrea ; Petzl, Wolfram ; Klee, Wolfgang: Infrared thermography of the udder surface of dairy cattle: Characteristics, methods, and correlation with rectal temperature. In: The Veterinary Journal 199 (2014), Nr. 1, 57-62

[4] Kunc, P.; Knizkova, I.; Prikryl, M. \& Maloun, J. Infrared Thermography As A Tool To Study The Milking Process: A Review Agricaltura Tropica Et Subtropica, 2007, 40, 29-32

[5] Franze, U.; Geidel, S.; Heyde, U.; Schroth, A.; Wirthgen, T. \& Zipser, S. Möglichkeiten des Einsatzes der Infrarot-Thermographie zur automatischen Gesundheitsüberwachung bei Milchkühen, Züchtungskunde, 2012, 84, 158-170

[6] Stewart, M., Stafford, K.J., Dowling, S.K., Schaefer, A.L., Webster, J.R. 2008. Eye temperature and heart rate variability of calves disbudded with or without local anaesthetic. Physiology \& Behavior, 93, 789-797.

[7] Stewart, M., Schaefer, A.L., Haley, D.B., Colyn J.J., Cook, N.J., Stafford, K.J., Webster, J.R. 2008. Infrared thermography as a non-invasive method for detecting fear-related responses of cattle to handling procedures. Animal Welfare, 17, 387-393.

[8] Schaefer, A.L., Cook, N.L., Bench, C., Chabot, B., Colyn, J., Liu, T., Okine, E., Stewart, M. Webster, J.R. 2012. The non-Invasive and automated detection of bovine respiratory disease onset in receiver calves using infrared thermography, Research in Veterinary Science 93, 928-935.

[9] Wirthgen, T.; Zipser, S.; Franze, U. \& Geidel, S.; Precise IR-Based Temperature Measuring - a Case Study for the Automatic Health Monitoring of Dairy Cows; SENSOR+TEST - IRS ${ }^{2}, 2011$

[10] Landgraf, T; Ein Betrag zur Automatisierung der temperaturbildbasierten Tierüberwachung, Technische Universität Dresden, PhD-Thesis, 2014

[11] Rößner, S.: Untersuchung zur Thermoregulation von Milchkühen, Hochschule für Technik und Wirtschaft Dresden (FH), diploma-thesis, 2005

[12] Wirthgen, T.; Zipser, S.; Franze, U.; Geidel, S.; Dietel, F. \& Alary, T.: Automatic Segmentation of Veterinary Infrared Images with the Active Shape Approach in Image Analysis Heyden, A. \& Kahl, F. (Eds.), Springer Verlag, 2011, 435-446

[13] Wirthgen, T.; Zipser, S.; Geidel, S. \& Franze, U.; Automatic Infrared Based Temperature Measuring System for Health Monitoring in Veterinary Applications; IEEE Sensors, 2011

[14] Church, J. S., P. R. Hegadoren, Paetkau, M.J. Miller, C.C. Regev-Shoshanib, G. Schaefer, A.L. SchwartzkopfGenswein, K.S. (2014). "Influence of environmental factors on infrared eye temperature measurements in cattle." Research in Veterinary Science 96(1): 220-226. 